\title{
Spectroscopic properties of rubber oxygenase RoxA from Xanthomonas sp., a new type of dihaem dioxygenase
}

Correspondence

Dieter Jendrossek dieter.jendrossek@imb. uni-stuttgart.de

Received 12 February 2010

Revised 8 April 2010

Accepted 15 April 2010

\author{
Georg Schmitt, ${ }^{1}$ Grazyna Seiffert, ${ }^{2}$ Peter M. H. Kroneck, ${ }^{2}$ \\ Reinhard Braaz ${ }^{1} \dagger$ and Dieter Jendrossek ${ }^{1}$ \\ ${ }^{1}$ Institut für Mikrobiologie, Universität Stuttgart, 70550 Stuttgart, Germany \\ ${ }^{2}$ Fachbereich Biologie, Universität Konstanz, 78457 Konstanz, Germany
}

Natural rubber [poly-(cis-1,4-isoprene)] is cleaved to 12-oxo-4,8-dimethyltrideca-4,8-diene-1-al (ODTD) by rubber oxygenase A (RoxA) isolated from Xanthomonas sp. RoxA has two c-type haem centres that show two distinct $\alpha$-bands at 549 and $553 \mathrm{~nm}$ in the dithionite-reduced state. A wellresolved midpoint potential $\left(E^{\prime \prime}\right)$ of $-65 \mathrm{mV}$ was determined for one haem by spectrophotometric titrations in the absence of dioxygen with dithionite and ferricyanide as reductant and oxidant, respectively. The midpoint potential of the second haem was not resolvable $\left(E^{0 \prime}\right.$ about -130 to $-160 \mathrm{mV}$ ). One of the two haems was reduced by NADH ( $549 \mathrm{~nm} \alpha$-band), similar to bacterial dihaem peroxidases. Evidence for an electron transfer between the two haems was provided by slow reduction of the second haem (553 $\mathrm{nm} \alpha$-band) upon incubation of the partially reduced enzyme at room temperature. Addition of imidazole or related compounds to RoxA led to UV/vis spectral features similar to those observed for partially reduced RoxA. Notably, reduction of RoxA with dithionite or $\mathrm{NADH}$, or binding of compounds such as imidazole, resulted in a reversible inactivation of the enzyme, unlike dihaem peroxidases. In line with this result, RoxA did not show any peroxidase activity. EPR spectra of RoxA as isolated showed two low-spin Fe(III) haem centres, with apparent $g$-values of 3.39, 3.09, 2.23, 1.92 and 1.50. A weak signal in the $g=6$ region resulting from a high-spin $\mathrm{Fe}$ (III) haem was also observed with a preparation-dependent intensity that disappeared in the presence of imidazole. Attempts to provide spectroscopic evidence for binding of the natural substrate (polyisoprene latex) to RoxA failed. However, experimental data are presented that RoxA is able to subtract redox equivalents from its substrate or from model compounds. In conclusion, RoxA is a novel type of dihaem dioxygenase with features clearly different from classical cytochrome $c$ peroxidases.

\section{INTRODUCTION}

Natural rubber (NR) or caoutchouc is a biopolymer that is synthesized by many plant species and by some fungi. NR has been commercially exploited for more than 100 years by cultivating and tapping the rubber tree (Hevea brasiliensis) at a level of several million tons per year.

tPresent address: Roche Diagnostics, Germany.

Abbreviations: CCP, cytochrome $C$ peroxidase; HRP, horseradish peroxidase; ICP-MS, inductively coupled plasma MS; NR, natural rubber; ODTD, 12-oxo-4,8-dimethyltrideca-4,8-diene-1-al; PMS, phenazine methosulfate.

A supplementary figure, showing redox titration of purified RoxA, and three supplementary tables, showing simulation parameters of the $X$ band EPR spectrum of RoxA, residual activities of RoxA in the presence of various compounds, and the effect of imidazole and related lowmolecular-mass compounds on the activity and UV/vis properties of RoxA, are available with the online version of this paper.
The natural polymer has an average molecular mass of about one million and is composed of two trans isoprene units at one end of the molecule followed by several hundreds to thousands of cis-1,4-isoprene units (Tanaka \& Sakdapipanich, 2001). The linear, non-branched polymer chains can be cross-linked by treatment with sulfur and heat (vulcanization), generating a material with superior physical and mechanical properties. Despite the development of chemosynthetic rubbers, the natural polymer is still required as a basic material for tyres, latex gloves, condoms, seals and many other items.

Naturally occurring NR is subject to biological mineralization cycles, and many reports on the isolation and characterization of rubber-degrading micro-organisms have been published (for overview, see Rose \& Steinbüchel, 2005, and references cited therein). Rubberdegrading bacteria either produce clearing zones on opaque latex agar, such as Xanthomonas sp. 35Y (Tsuchii 
\& Takeda, 1990) and many actinomycetes (Jendrossek et al., 1997), or grow adhesively on rubber without clearing-zone formation, such as several Gordonia strains (Linos et al., 1999, 2002). Based on identified intermediates that had been isolated from rubber-grown bacteria (Bode et al., 2000; Tsuchii et al., 1985; Tsuchii \& Takeda, 1990), a biochemical degradation route has been proposed (Bode et al., 2001; Rose \& Steinbüchel, 2005). Meanwhile, two candidate proteins have been described that are involved in the primary attack of the polyisoprene carbon backbone. One is the latex-clearing protein (Lcp) of Streptomyces sp. K30 (Rose et al., 2005) and the other is rubber oxygenase RoxA of Xanthomonas sp. Lcp and RoxA are apparently completely different polypeptides with no significant amino acid similarities. RoxA is a dihaem oxygenase releasing lowmolecular-mass oligoisoprene units as products. 12-Oxo4,8-dimethyltrideca-4,8-diene-1-al (ODTD) has been identified as the major product under in vitro conditions together with a homologous series of minor metabolites that differ from the major degradation product only in the number of repetitive isoprene units between terminal functions, $\mathrm{CHO}-$ $\mathrm{CH}_{2^{-}}$and $-\mathrm{CH}_{2}-\mathrm{COCH}_{3}$ (Braaz et al., 2004). Isotope labelling experiments have revealed that RoxA is a dioxygenase (Braaz et al., 2005). A large set of experiments was carried out to investigate the reactivity of the RoxA haem centres towards substrates, reductants, oxidants, inhibitors and well-known haem ligands, including imidazole and related compounds.

\section{METHODS}

Cultivation of bacteria and purification of rubber oxygenase (RoxA). Xanthomonas sp. 35Y (Tsuchii \& Takeda, 1990) was grown in nutrient broth (NB) or in a mineral salts medium (MSM) with 0.1$0.2 \%$ purified rubber latex at $30{ }^{\circ} \mathrm{C}$. For isolation of RoxA from Xanthomonas sp. wild-type, $24250 \mathrm{ml}$ cultures were grown for about 10-14 days, and RoxA was purified from the combined cell-free culture fluid as described previously (Braaz et al., 2005). For purification of recombinantly expressed RoxA, Xanthomonas sp. harbouring p4782.1::roxA (p4782.1 is a mobilizable broad-hostrange vector suitable for rhamnose-dependent expression of cloned genes and confers resistance against kanamycin) was grown in 150.51 cultures of nutrient broth (NB) or modified Luria-Bertani (LB) broth (yeast extract of LB replaced by NB) supplemented with $0.1 \% \mathrm{~L}-$ rhamnose for $60 \mathrm{~h}$ at $30{ }^{\circ} \mathrm{C}$ by continuous shaking, as described previously (Hambsch et al., 2010). Purification of RoxA was performed from the combined cell-free culture fluid.

Purification of RoxA. RoxA was purified at room temperature using an ÄKTA FPLC system (GE Healthcare). Cell-free supernatant of Xanthomonas sp. p4782.1:: roxA culture was concentrated by ultrafiltration (30 kDa cut-off) and passed through a Q-Sepharose Fast Flow column (Q-FF 50/11; GE Healthcare) pre-equilibrated with $20 \mathrm{mM}$ Tris/ $\mathrm{HCl}\left(\mathrm{pH} \mathrm{7.7)}\right.$ at a flow rate of $3 \mathrm{ml} \mathrm{min}^{-1}$. RoxA was collected in the flow-through and separated from proteins that bound to the column at $\mathrm{pH}$ 7.7. In a second step, the RoxA-containing flowthrough was passed through the same column but equilibrated with $20 \mathrm{mM}$ Tris/HCl ( $\mathrm{pH}$ 8.5). RoxA was bound at alkaline $\mathrm{pH}$ and eluted at $\sim 50 \mathrm{mM} \mathrm{NaCl}$. RoxA-containing fractions were combined and stored at $-70{ }^{\circ} \mathrm{C}$. The RoxA was pure $(\sim 95 \%)$, as judged by SDS-PAGE analysis and subsequent staining with silver. If highly purified RoxA was necessary, an additional step involving a hydroxyapatite column [several runs with a Bio-Scale CHT5-I column (Bio-Rad)] equilibrated with potassium phosphate (KP) buffer ( $5 \mathrm{mM}, \mathrm{pH}$ 6.2) was used after changing the buffer of the RoxA pool with a HiPrep 26/10 desalting column (GE Healthcare) after the second step of Q-Sepharose gel-filtration chromatography. RoxA was eluted with a linear gradient of 5-200 mM KP at $40 \mathrm{mM}$. RoxA fractions were pooled and concentrated by ultrafiltration $(30 \mathrm{kDa}$ cut-off) to $\sim 5 \mathrm{mg} \mathrm{ml}^{-1}$. The addition of $300 \mathrm{mM} \mathrm{NaCl}$ was necessary to prevent precipitation of RoxA. Purity was tested by SDS-PAGE and by determination of the ratio of absorption at 406 and $280 \mathrm{~nm}$, which was 1.35 for highly pure RoxA after hydroxyapatite chromatography and final concentration. Purified RoxA was frozen in liquid nitrogen and stored at $-70{ }^{\circ} \mathrm{C}$.

Assay of RoxA. The following conditions were used for product analysis of RoxA-catalysed rubber degradation by HPLC analysis: the reaction mixture contained $100 \mu \mathrm{l}$ purified RoxA $\left(2 \mu \mathrm{g} \mathrm{ml}^{-1}\right)$, rubber latex $(0.2 \%, \mathrm{w} / \mathrm{v}$, emulsion) and KP buffer $(100 \mathrm{mM}, \mathrm{pH} 7.0)$ in a total volume of $1 \mathrm{ml}$. The reaction was carried out at $40{ }^{\circ} \mathrm{C}$ for $3 \mathrm{~h}$ in a test tube sealed with Parafilm. The mixture was extracted with ethyl acetate or diethyl ether, dried, dissolved in 100-200 $\mu$ l methanol, and then subjected to HPLC analysis and/or to carbonyl content determination (Katz \& Keeney, 1966). Mixtures without RoxA and with heat-inactivated RoxA $\left(10 \mathrm{~min}, 95{ }^{\circ} \mathrm{C}\right)$ served as controls. One unit (U) of RoxA activity corresponds to one micromole carbonyl function generated per minute.

Peroxidase assay. Peroxidase activity was assayed as described by Mason et al. (2001). RoxA was incubated in $100 \mathrm{mM}$ sodium phosphate buffer ( $\mathrm{pH} 7$ ) containing $5 \mathrm{mM}$ 2,4-dichlorophenol, $3.2 \mathrm{mM} 4$-aminoantipyrene and $1 \mathrm{mM}$ hydrogen peroxide, and the increase of $A_{510}$ was followed. Alternatively, pyrogallol $(420 \mathrm{~nm})$, guaiacol $(436 \mathrm{~nm})$ and $\mathrm{Fe}(\mathrm{II})$ (horse heart) cytochrome $c$ (decrease at $550 \mathrm{~nm}$ ) were used as electron donors. Horseradish peroxidase (HRP) was used as a reference.

Transformation of Xanthomonas sp. A $100 \mathrm{ml}$ volume of NB medium in a $500 \mathrm{ml}$ Erlenmeyer flask was inoculated with 0.01 volumes of an NB seed culture and grown overnight at $30{ }^{\circ} \mathrm{C}$ until the $\mathrm{OD}_{600}$ reached 0.4-0.6. Cells were centrifuged in $50 \mathrm{ml}$ Falcon tubes aseptically at $4{ }^{\circ} \mathrm{C}$ and $5100 \mathrm{~g}$ for $15 \mathrm{~min}$. The supernatant was discarded and the pellet was resuspended in about $0.2 \mathrm{ml}$ of the supernatant. It was important to ensure that the culture was kept on ice during all manipulation steps. Cells in Falcon tubes were diluted with $40 \mathrm{ml}$ ice-cold $0.1 \mathrm{M}$ HEPES buffer that had been titrated to $\mathrm{pH} 7.0$ by the addition of $1 \mathrm{M}$ Tris base, and were centrifuged ( $15 \mathrm{~min}, 5100 \mathrm{~g}, 4{ }^{\circ} \mathrm{C}$ ) and resuspended as described above. The washing procedure was repeated with $40 \mathrm{ml} 10 \%(\mathrm{v} / \mathrm{v})$ glycerol that had been adjusted to neutral $\mathrm{pH}$ by the addition of a few drops of $0.1 \mathrm{M}$ HEPES-Tris, $\mathrm{pH}$ 7. Cells were resuspended in about $0.2 \mathrm{ml}$ of the remaining supernatant and were then ready for use in electrotransformation experiments. Cells were kept on ice until use. A $75 \mu 1$ volume of electrocompetent cells was mixed with 50-500 ng DNA in an ice-cold electroporation cell. Electroporation was performed at $25 \mu \mathrm{F}, 200 \Omega, 1.5 \mathrm{kV}$. Cells were transferred to $0.6 \mathrm{ml}$ fresh NB medium and incubated for up to $3 \mathrm{~h}$ at $30{ }^{\circ} \mathrm{C}$ before aliquots were plated on selective solid media (NB supplemented with 20-30 $\mu \mathrm{g}$ kanamycin $\mathrm{ml}^{-1}$ ). Determination of c.f.u. $\mathrm{ml}^{-1}$ after electroporation by plating appropriate dilutions on NB agar was useful because a high loss of viability after electroporation was frequently observed and resulted in insufficient electroporation efficiency. Alternatively, mobilizable plasmids were transferred to Xanthomonas sp. via conjugation with Escherichia coli S17-1. The efficiency of conjugative transfer of DNA was about two to three orders of magnitude higher than that of electro-transformation. 
Haem staining. Haem staining was performed after separation of RoxA samples by SDS-PAGE and subsequent assay for pseudoperoxidase activity of the RoxA haem groups. The gels were washed with water and incubated at room temperature in a solution consisting of $15 \mathrm{ml}$ $3,3^{\prime}-5,5^{\prime}$-tetramethylbenzidine ( $1.5 \mathrm{mM}$ in methanol), $35 \mathrm{ml} 0.25 \mathrm{mM}$ sodium acetate, $\mathrm{pH} \mathrm{5}$, and $26 \mathrm{mM} \mathrm{H}_{2} \mathrm{O}_{2}$. A blue colour indicated the presence of haem-dependent pseudoperoxidase activity. Protein concentration was determined by the Bradford method (Bradford, 1976) and by commercial bicinchoninic acid (BCA) assay (Pierce).

Iron analysis. Iron was determined by Spuren-analytisches Laboratorium Dr Baumann (Maxhütte-Haidhof, Germany) using inductively coupled plasma MS (ICP-MS).

UV/vis-monitored oxidation-reduction. Potentiometric titrations were performed under the exclusion of dioxygen (Argon) in a Thunberg cell, at $\mathrm{pH} 7.0$ and $25^{\circ} \mathrm{C}$, by stepwise addition of sodium dithionite (reduction) or potassium ferricyanide (oxidation) to $8 \mu \mathrm{M}$ RoxA in $5 \mathrm{mM}$ potassium phosphate buffer, containing $1 \mu \mathrm{M}$ of the following redox mediators: $N, N, N^{\prime}, N^{\prime}$-tetramethyl phenylenediamine $\left(E^{0 \prime}+260 \mathrm{mV}\right), 2,6$-dichlorophenolindophenol $(+217 \mathrm{mV})$, phenazine methosulfate (PMS) $(+80 \mathrm{mV})$, indigo trisulfonate $(-70 \mathrm{mV})$, indigo disulfonate $(-125 \mathrm{mV})$, 2-hydroxy-1,4-naphthoquinone $(-152 \mathrm{mV})$, anthraquinone-2-sulfonate $(-225 \mathrm{mV})$, phenosafranine $(-252 \mathrm{mV})$ and methyl viologen $(-440 \mathrm{mV})$. All solutions were made anoxic through several cycles of argon and vacuum; the values of the potentials were recorded when they changed by less than \pm 2 $\mathrm{mV}$ within $5 \mathrm{~min}$. The UV/vis spectra were corrected for turbidity and for contributions from the mediators; potentials are reported versus the standard hydrogen electrode (SHE).

Alternatively, the haem midpoint potentials were determined by the xanthine/xanthine oxidase redox system (Hopkins \& Williams, 1995) in an atmosphere of dinitrogen, with resorufin $(-51 \mathrm{mV})$, indigo trisulfate $(-78 \mathrm{mV})$, indigo disulfate $(-125 \mathrm{mV})$ or 2-hydroxynaphthoquinone $(-152 \mathrm{mV})$ as redox dye. RoxA $(3-4 \mu \mathrm{M})$, redox dye $(5-15 \mu \mathrm{M})$ and xanthine $(200-300 \mu \mathrm{M})$, in $100 \mathrm{mM} \mathrm{KP}$ buffer $(\mathrm{pH} 7)$, were made free of dioxygen in a Thunberg cell sealed by a double rubber septum. The reaction was started by the addition of xanthine oxidase (XO; $5-10 \mathrm{mU}$ ) from a concentrated solution in buffer. Reduction was monitored continuously by the difference spectrum (absorption with XO minus absorption without $\mathrm{XO}$ ) for $\sim 4-10 \mathrm{~h}$. The redox potential difference was calculated as described by Hopkins \& Williams (1995) by plotting $\ln [(\text { ox }) /(\text { red })]_{\text {RoxA }}$ of RoxA monitored at $418 \mathrm{~nm}$ (increase) against $\ln [(\mathrm{ox}) /(\text { red })]_{\text {Dye }}$ of the redox dye monitored at its specific absorption maximum (decrease). At equilibrium, the system potentials $E_{\mathrm{RoxA}}=E_{\mathrm{RoxA}}^{0^{\prime}}+\mathrm{R} T / \mathrm{F} z_{\mathrm{RoxA}} \times \ln [(\mathrm{ox}) /(\text { red })]_{\text {RoxA }}$ and $E_{\text {Dye }}=E_{\text {Dye }}^{0^{\prime}}+\mathrm{R} T / \mathrm{F} z_{\text {Dye }} \times \ln [(\mathrm{ox}) /(\text { red })]_{\text {Dye }}$ are equal $[\mathrm{R}=$ gas constant, $T=$ temperature $(\mathrm{K}), \mathrm{F}=$ Faraday constant, $z=$ number of electrons accepted]. Because the midpoint potential of the redox dye is known, the potential of RoxA can be calculated when $\ln [(\mathrm{ox}) /(\mathrm{red})]_{\text {Dye }}$ is zero. Rearrangement gives the equation $E_{\mathrm{RoxA}}^{0^{\prime}}=E_{\mathrm{Med}}^{0^{\prime}}-\mathrm{RT} / \mathrm{F} z_{\mathrm{RoxA}} \times \ln [(\mathrm{ox}) /$ (red) $]_{\text {RoxA }}$.

Further oxidoreduction titrations of RoxA were performed by photochemical reduction with the 5-deazaflavin (5-deaza-10-methyl-3-sulfopropyl-isoalloxazine) system (Massey \& Hemmerich, 1978), using RoxA (3-6 $\mu \mathrm{M})$, 5-deazaflavin $(1-2 \mu \mathrm{M})$ as catalyst and Tris or EDTA (5$10 \mathrm{mM}$ ) as electron donor in $100 \mathrm{mM} \mathrm{KP}$ buffer ( $\mathrm{pH} 7.0$ ) at room temperature ( $\mathrm{N}_{2}$ atmosphere). Reduction was initiated by variable times of exposure to a light source (30-180 s); reoxidation was done by addition of potassium ferricyanide, $\mathrm{K}_{3}\left[\mathrm{Fe}(\mathrm{CN})_{6}\right]$. UV/vis spectroscopy of RoxA in the absence of dioxygen was performed by removing dioxygen from RoxA as isolated by eight to 10 cycles of vacuum and flushing with dinitrogen gas (nitrogen 4.6, $99.996 \%$, oxygen $\leqslant 5$ p.p.m.).

EPR spectroscopy. Perpendicular-mode X-band EPR spectra were recorded on a Bruker Elexsys E500 instrument with an ER 049 X microwave bridge. The system was equipped with an Oxford Instruments ESR 900 helium cryostat controlled by an ITC 503 temperature device. The modulation frequency was $100 \mathrm{kHz}$ and the modulation amplitude was typically $1 \mathrm{mT}$. The measurements were performed with a Bruker 4122 SHQE cavity at $\sim 9.38 \mathrm{GHz}$, in $4 \mathrm{~mm}$ quartz tubes (705-PQ-9.50, Wilmad); the sample volume was $250 \mu \mathrm{l}$. Parallel-mode X-band spectra were recorded on a Bruker ESP 300 spectrometer equipped with an ER 4116 bimodal cavity and the Air Products Helitran liquid helium flow system. EPR spectra were simulated with the program WEPR (Neese, 1995).

\section{RESULTS}

\section{Biochemical characterization of RoxA purified from Xanthomonas sp.}

RoxA was isolated from a polyisoprene latex-grown Xanthomonas sp. culture and purified to homogeneity by the criterion of SDS-PAGE, as described previously (Braaz et al., 2005). The purified enzyme contained two (1.9) haems and two (2.3) iron atoms per molecule of RoxA, as determined by the haem-pyridine chromophore assay $\left(\varepsilon_{551}=29 \mathrm{mM}^{-1} \mathrm{~cm}^{-1}\right)$ and by ICP-MS, respectively. These analytical data are in line with the presence of the two classical $c$-type haem-binding motifs $\mathrm{CXXCH}$ found in the amino acid sequence of RoxA (accession no. AY230855). Specific activity $\left(300 \mathrm{mU} \mathrm{mg}{ }^{-1}\right.$ ) and UV/vis absorption properties were almost identical to those reported previously (Braaz et al., 2004, 2005). The yield of pure RoxA varied from preparation to preparation (1-5 mg $\mathrm{l}^{-1}$ ) and depended on the number of remaining latex particles left at the end of the growth phase, typically after 11-14 days of incubation in latex medium. Most likely, a portion of the RoxA remained bound to latex particles, thus reducing the yield of RoxA. Numerous attempts to express recombinant RoxA in E. coli or other Gram-negative bacteria were not successful. Even co-expression of roxA with the cytochrome $c$ maturation $(\mathrm{ccm})$ genes (Arslan et al., 1998; Thöny-Meyer, 1997) did not result in significant expression of RoxA. Thus, a homologous expression system in Xanthomonas sp. was established by construction of a recombinant Xanthomonas sp. strain with roxA cloned in a broad-host-range plasmid, p4782.1, under the control of a rhamnose-dependent promoter. About $6 \mathrm{mg}$ purified RoxA was obtained from 11 supernatant of recombinant Xanthomonas sp. (p4782.1:: roxA) cultures on NB medium supplemented with $0.1 \%$ rhamnose. RoxA purified from recombinant Xanthomonas sp. was active and did not differ significantly in its biochemical properties from RoxA that had been purified from latex-grown Xanthomonas sp. wild-type.

\section{Spectroscopic and redox properties of RoxA haem centres and relationship to bacterial cytochrome $c$ peroxidases (CCPs)}

UV/vis spectra of pure RoxA as isolated (oxidized) and after addition of dithionite in the absence of dioxygen showed absorption maxima typical for $c$-type haem centres in the oxidized $\mathrm{Fe}(\mathrm{III})$ and reduced $\mathrm{Fe}(\mathrm{II})$ state, respectively 

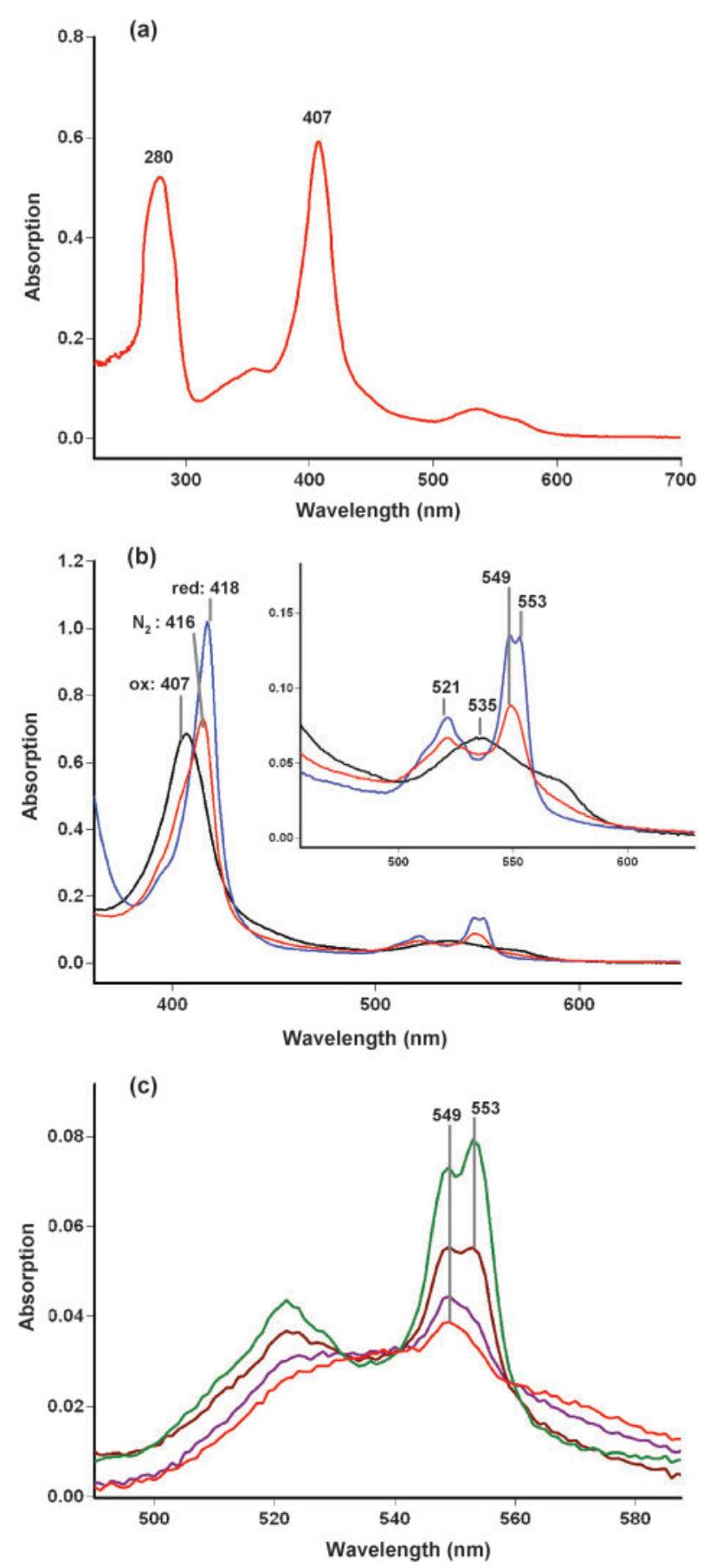

(Fig. 1a, b). Dithionite-reduced RoxA had a Soret band at $418 \mathrm{~nm}$, the $\beta$-band was at $522 \mathrm{~nm}$, and the $\alpha$-band was split into two separate peaks at 549 and $553 \mathrm{~nm}$. These optical properties, as well as some similarity between the amino acid sequences of RoxA and bacterial CCPs, including the presence of two $c$-type haem-binding motifs and a conserved region around His H17 $_{5}$ (Jendrossek \& Reinhardt, 2003), suggest that RoxA is distantly related to CCPs. However, the RoxA polypeptide is much larger $(71.5 \mathrm{kDa})$ in comparison with most bacterial CCPs
Fig. 1. UV/vis spectra of RoxA. (a) RoxA as isolated from latex culture. (b) RoxA as isolated from latex culture (ox, oxidized; black line), after complete reduction with sodium dithionite (red, reduced; red line) and after incubation under a $\mathrm{N}_{2}$ atmosphere $\left(\mathrm{N}_{2} ;\right.$ green line) for $48 \mathrm{~h}$. The double maximum of the $\alpha$-band at $549 / 553 \mathrm{~nm}$ indicates the presence of two different haem groups. A partial, slowly continuing reduction of both haem groups (one more readily than the other) was observed after anaerobic incubation for longer periods. The inset figure shows an enlargement of the $\alpha$-region. (c) $\mathrm{UV} / \mathrm{vis}$ spectrum of RoxA in the region of the $\alpha$-bands upon incubation with NADH/PMS. Both haem centres could be reduced after prolonged incubation times. A time-dependent (from black to blue) increase of the $549 \mathrm{~nm}$ peak was observed.

(30-40 kDa). UV/vis-monitored potentiometric titrations of RoxA with dithionite (reduction) and ferricyanide (oxidation) showed fully reversible behaviour of the haem centres in RoxA. The redox mediators used in the titrations did not interfere with the absorption spectra of RoxA. Two Nernst equations with separately variable midpoint potentials had to be used to fit the experimental data, with a first midpoint potential $E^{0 \prime}$ at $-65 \mathrm{mV}$. The redox step at the more negative potential was not resolved $\left(E^{0 \prime}\right.$ about -130 to $-160 \mathrm{mV}$; Supplementary Fig. S1). Several repetitions of the experiment did not result in a better resolution of the more negative potential (results not shown).

Experiments using the xanthine/xanthine oxidase reduction system with different redox dyes were performed to obtain a better resolution. Best results were obtained when indigodisulfate $\left(E^{0 \prime}-125 \mathrm{mV}\right)$ or hydroxynaphthoquinone $\left(E^{0 \prime}\right.$ $-152 \mathrm{mV}$ ) was used, and the midpoint potential of RoxA was determined to be between -110 and $-160 \mathrm{mV}$, which is in agreement with the results from spectrophotometric determinations. However, a more precise determination and separation of the two potentials was not possible. In conclusion, RoxA differs from bacterial CCPs in its redox properties; CCPs generally have clearly separated midpoint potentials $\left(\Delta E^{0 \prime} \sim 650 \mathrm{mV}\right.$; see Table 1 for a comparison of RoxA and CCP properties) (Fülöp et al., 1995).

Determination of the number of electrons that can be taken up by RoxA was performed by UV/vis-monitored titration of RoxA using the 5-deazaflavin photoreduction system. RoxA again showed fully reversible redox behaviour (not shown). After complete photoreduction by the addition of stoichiometric amounts of ferricyanide (with respect to the number of haem groups present) the original (oxidized) spectrum was restored by almost $90 \%$, indicating that approximately two electrons can be abstracted from reduced RoxA (one electron per haem). However, complete reoxidation of RoxA required at least a threefold molar excess of ferricyanide and long incubation times.

\section{EPR spectroscopy}

The EPR technique is a valuable tool to characterize the spin states of haem centres. The low-temperature EPR spectrum of RoxA (as isolated) recorded at the X-band 
Table 1. Comparison of RoxA with bacterial CCPs

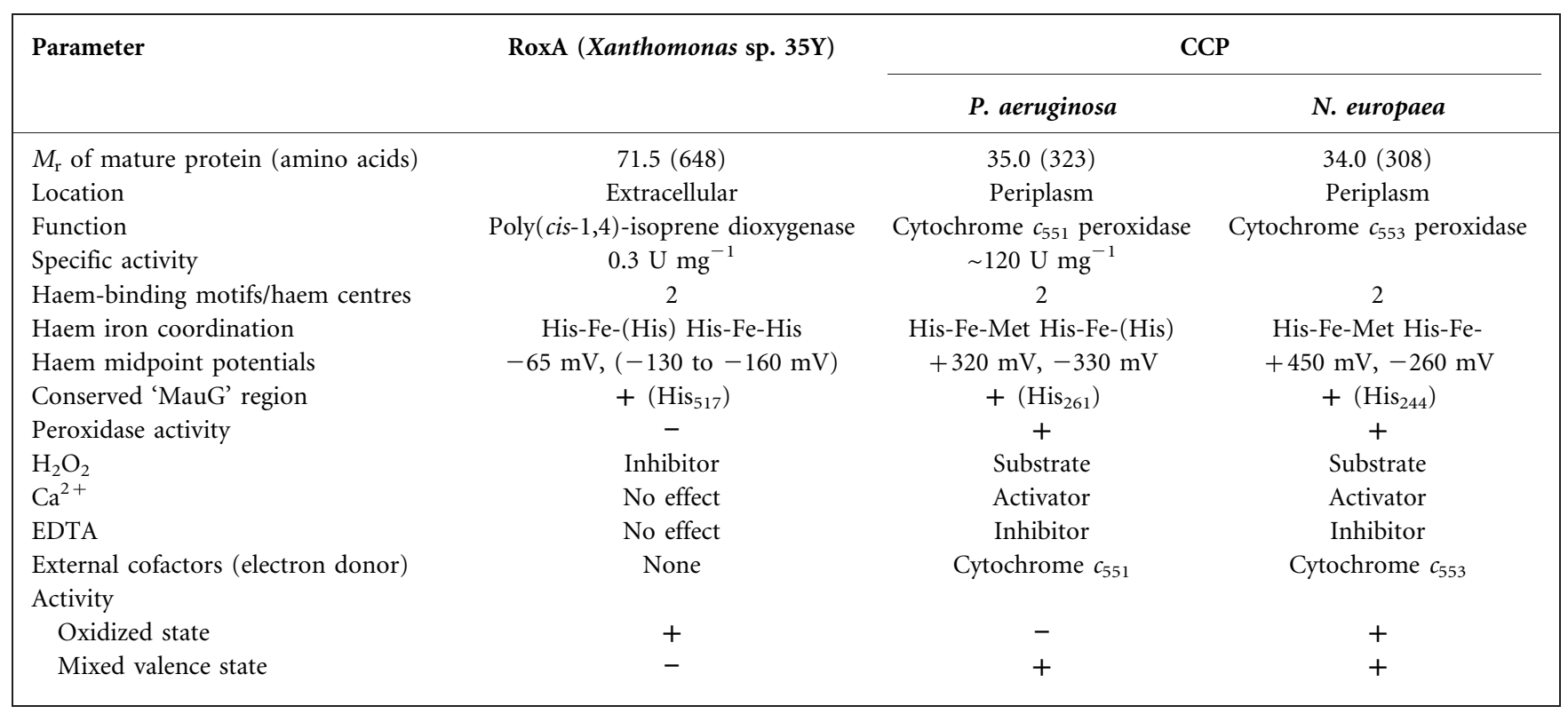

(Fig. 2) showed major resonances at $g=3.09,2.23$ and $\sim 1.50$, which are typical for hexacoordinate low-spin Fe(III) haem centres (Palmer, 1983), with histidine residues as the fifth and sixth ligands to the iron, having nearly parallel imidazole planes similar to other $c$-type cytochromes. A second set of resonances was found at $g=3.39$ and $g=1.92$, originating from a second low-spin $\mathrm{Fe}(\mathrm{III})$ centre, with the imidazole planes of the axial histidine ligands being nearly perpendicular (Walker, 1999). The $g$-value of this centre at high magnetic field was extremely broad and thus hard to detect under the experimental conditions. The complete set of resonances was assigned to two magnetically isolated haem centres, since their $g$-values were frequency-independent. Furthermore, there was no signal in the parallel-mode Xband spectrum originating from an integer spin system (data not shown). Spin quantification $\left(\mathrm{CuSO}_{4}\right.$ standard) of the former signal yielded 0.8 low-spin $\mathrm{Fe}$ (III) haem centre. There was a third signal in the EPR spectrum of RoxA as isolated at around $g=6.1$, indicative of high-spin $\mathrm{Fe}$ (III) haem with a weak ligand in the sixth position trans to the axial histidine that constitutes the fifth ligand (Palmer, 1983). The relative intensities of the signals at low and high magnetic field varied moderately from preparation to preparation of the extracellular dihaem enzyme. Computer simulations showed that there were roughly equal amounts of the high-spin and low-spin Fe(III) species. The signal at $g=4.3$ was assigned to non-specifically bound iron, in agreement with the analytical data obtained for haem (1.9) and iron (2.3). The simulated spectrum (Fig. 2) represents three Fe(III) haem species: two low-spin Fe(III), at $g=3.39$, $3.09,2.23,1.92,1.5$; and one high-spin Fe(III), at $g=6.1$ (with the simulation parameters compiled in Supplementary Table S1). The reaction of RoxA with dithionite led to the disappearance of all EPR signals (not shown). The reduction

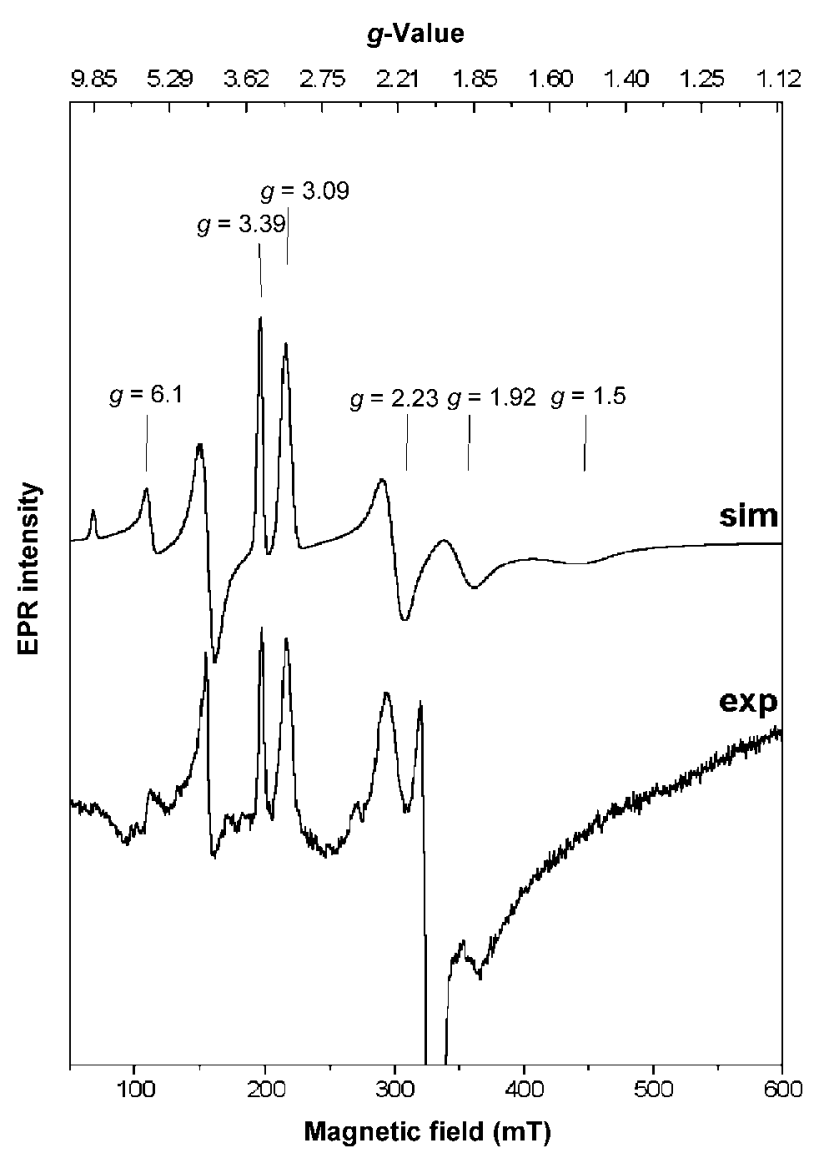

Fig. 2. (a) Experimental (exp) and simulated (sim) perpendicularmode X-band EPR spectra of RoxA (as isolated) from Xanthomonas sp. at $9.38 \mathrm{GHz}, 10 \mathrm{~K}, 2 \mathrm{~mW}$. Protein at $0.03 \mathrm{mM}$ in $5 \mathrm{mM} \mathrm{1,3-diaminopropane,} \mathrm{pH}$ 8.0. Simulated parameters are given in Supplementary Table S1. 
of $\mathrm{Fe}$ (III) by dithionite was reversible by the addition of air. The high-spin signal at $g=6.1$ was often more intense in dithionite-reduced RoxA after reoxidation under air than in RoxA as isolated (results not shown).

\section{Effects of dioxygen removal and of reducing compounds on UV/vis spectra and activity of RoxA}

Dioxygen was removed from RoxA preparations by eight to 10 cycles of vacuum and flushing with dinitrogen gas. No significant changes were observed in the EPR spectrum (results not shown). However, UV/vis spectroscopy of RoxA under $\mathrm{N}_{2}$ atmosphere showed a time-dependent increase in the absorbance at 549-553 nm and a concomitant shift of the Soret band from $406 \mathrm{~nm}$ to higher wavelengths $(418 \mathrm{~nm})$. The observed effects corresponded to the effects of a partial reduction of RoxA (Fig. 1b). Repetition of this experiment and recording of the UV/vis spectra after different incubation periods with dinitrogen gas $(1 \mathrm{~min}$ to $72 \mathrm{~h}$ ) indicated that the $549 \mathrm{~nm} \alpha$-band was reproducibly the first to increase, within hours; the $553 \mathrm{~nm}$ $\alpha$-band only increased after prolonged incubation times (up to days). Chemical removal of dioxygen by addition of pyrogallol resulted in similar but more rapid spectral changes. Controls under air showed no significant changes in the UV/vis spectrum (results not shown).

Most known bacterial CCPs (e.g. those of Pseudomonas aeruginosa), with the exception of Nitrosomonas europaea (Arciero \& Hooper, 1994) and Methylococcus capsulatus (Zahn et al., 1991) CCPs, require a reduction of one of the two haem centres for activity (mixed-valence state). RoxA, however, was active in the fully oxidized state as isolated in the presence of dioxygen. To investigate the effect of the redox state of the haem groups in RoxA, mild chemical reduction was performed. About a 100 -fold excess of $\mathrm{NADH}$ was added to RoxA as isolated $(2-5 \mu \mathrm{M})$ in the presence of the electron mediator PMS. Dioxygen was removed and replaced by dinitrogen. A time-dependent increase of absorbance in the area of the $\alpha$-bands was detected (Fig. 1c) that was not present in controls without PMS. This increase was significantly stronger and appeared much faster than that obtained without NADH/PMS (Fig. 1b). Apparently, the haem centres of RoxA can be reduced by NADH. Similar to the results obtained for dithionite-treated RoxA, one haem started to be reduced first and at lower amounts of NADH/PMS, which was visible by the earlier and more pronounced increase of the $549 \mathrm{~nm}$ band relative to the increase at $553 \mathrm{~nm}$ (Fig. 1c). It was not possible temporally to separate the increase at both wavelengths. As observed with dithionite-reduced RoxA, exposure of NADH/PMS-treated RoxA to air led to reoxidation within a few minutes (results not shown). An almost complete reduction of RoxA was found even under oxic conditions when a high molar excess of NADH $(10 \mathrm{mM})$ was used (results not shown). Treatment of RoxA with NADH/PMS resulted in strong inactivation $(10 \%$ residual activity at $1 \mathrm{mMNADH} / \mathrm{PMS}$ ) and indicated that RoxA, unlike most bacterial CCPs, is inactive in the partially reduced state (Table 2 and Supplementary Table S2).

Addition of external nitrogen-containing compounds that could serve as potential haem ligands, such as imidazole, pyridine and related compounds, led to remarkable effects on the activity of RoxA and its UV/vis spectra: incubation of RoxA with $1 \mathrm{mM}$ imidazole, 1-methylimidazole, pyrazole, pyrazine, 2-methylpyrazine, pyridine, 4-methylpyrimidine or pyridazine resulted in significant inactivation of RoxA and caused significant spectral changes (i.e. a shift of the Soret band to longer wavelengths and an increase at 549 nm; Fig. 3a, Supplementary Table S3). The individual velocity of each effect was concentration-dependent for each compound and the reaction proceeded to a concentration-independent end point (molar excess of the compound). Depending on the chemical structures of the test compounds, the spectral changes in difference spectra (UV/vis spectrum of RoxA as isolated minus the UV/vis spectrum recorded after incubation with the test compound) differed slightly (i) in the wavelength of the Soret

Table 2. Effect of different compounds (1 mM) on RoxA activity

The activity assay was performed by HPLC quantification of ODTD after incubation overnight, as described in Methods.

\begin{tabular}{|lc|}
\hline Compound & Residual activity (\%) \\
\hline Hydrogen peroxide & $\leqslant 5$ \\
Ferricyanide & 25 \\
Potassium permanganate & 21 \\
Sodium dithionite & 26 \\
NADH/PMS & 10 \\
Ascorbate & 16 \\
Squalene & 5 \\
$\alpha$-Tocopherol & $\leqslant 5$ \\
-Tocotrienol & 62 \\
$\beta$-Carotene & $\leqslant 5$ \\
Quinone & 11 \\
Hydroxylamine & $\leqslant 5$ \\
Hydrazine & $\leqslant 5$ \\
Phenylhydrazine & $\leqslant 5$ \\
Sodium azide & 86 \\
Ammonium hydroxide & $>95$ \\
CaCl & $>95$ \\
NaCl & $>95$ \\
NaF & 92 \\
FeSO $_{4}$ & 91 \\
FeCl & \\
Imidazole & 89 \\
Histidine & 50 \\
Pyrogallol & 80 \\
DMSO & 43 \\
Sodium hypochlorite & 80 \\
Formic acid & \\
Oxalic acid & \\
& \\
\hline
\end{tabular}



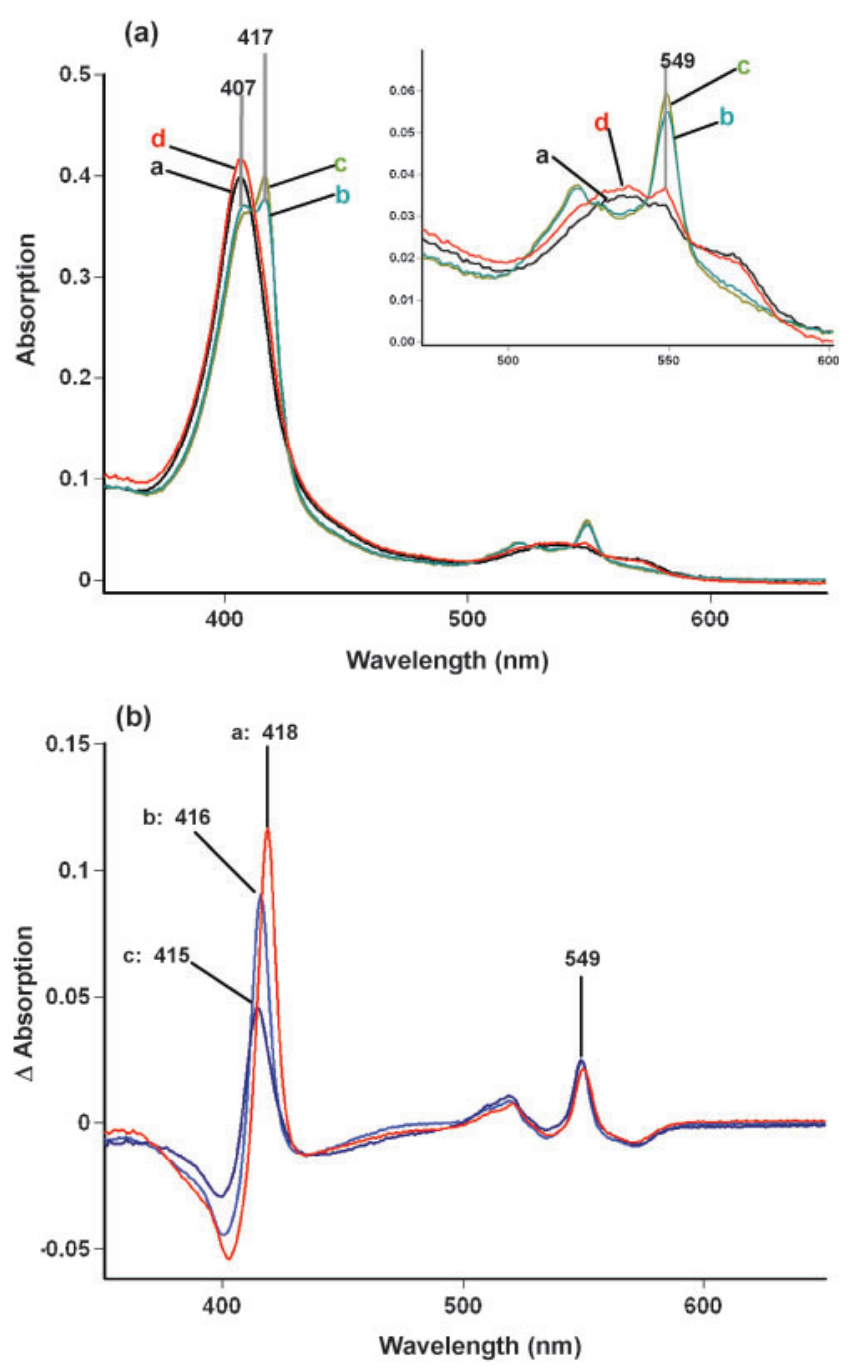

Fig. 3. (a) UV/vis spectra of RoxA as isolated (a, black line) and RoxA in the presence of $1 \mathrm{mM}$ imidazole (b, blue line), 1methylimidazole (c, green line) and 2-methylimidazole (d, red line), incubated for $1 \mathrm{~h}$ at room temperature under air. A double Soret maximum at 407 and $417 \mathrm{~nm}$ and an $\alpha$-band at $549 \mathrm{~nm}$ (inset) appeared after the addition of imidazole and 1-methylimidazole. (b) Difference spectra of RoxA with imidazole ( $a$, red line), pyridine (b, black line) and pyrazine (c, green line) at the end point of the reaction minus the spectrum of RoxA as isolated (all under air).

region, (ii) in the intensity of the signals, and (iii) in the relative proportions of the changes in the Soret region to the changes of the $\alpha$ - and $\beta$-bands (Fig. 3b). Interestingly, addition of imidazole or related compounds resulted in an increase of the $549 \mathrm{~nm} \alpha$-band, but no concomitant shift to $553 \mathrm{~nm}$ was observed.

Compounds related in structure to imidazole but with a voluminous side group in the direct vicinity of the nitrogen atom with the free electron pair, such as a methyl group, had no or only a small effect on RoxA activity and UV/vis spectra (Fig. 3a, Supplementary Table S3).
When the low-molecular-mass test compounds (imidazole, 1-methylimidazole, pyrazole, pyridine, pyrazine and pyridazine) were removed from the buffer by gel filtration, RoxA activity was recovered, although the observed changes in the UV/vis spectra remained (except for pyrazole), which indicated that the compounds were still bound to the enzyme. Removal of imidazole and 1methylimidazole resulted in only partial recovery $(\sim 50$ and $70 \%$, respectively) of the activity.

Linear nitrogen-containing compounds such as hydrazine, phenylhydrazine and hydroxylamine, which are known as catalase/peroxidase inhibitors (Wariishi et al., 2000), resulted in inactivation of RoxA (Table 2 and Supplementary Table S2). However, only minimal spectral changes were observed in the wavelength of the signals and a general decrease of haem absorption was detected, suggesting that these compounds led to partial destruction of the enzyme. This conclusion was supported by the detection of a significant increase of the signal for free iron $(g=4.3)$ in EPR measurements (results not shown).

\section{Effect of oxidizing compounds}

The results described above showed that compounds which can reduce or bind to one of the haem groups are potent inhibitors of the RoxA-mediated cleavage reaction. Next, oxidizing compounds were tested for their effect on RoxA (Table 2 and Supplementary Table S2). Hydrogen peroxide turned out to be a potent inhibitor of RoxA. Concentrations of $0.1 \mathrm{mM}$ or greater completely inhibited the reaction and $10 \mu \mathrm{M}$ hydrogen peroxide still inhibited the reaction by $80 \%$. Hydrogen peroxide did not change the UV/vis spectrum of RoxA (results not shown). Treatment of RoxA with hydrogen peroxide at $1 \mathrm{mM}$ or higher resulted in slow destruction of the protein, similar to the effect of hydrazine. An interesting effect was found when catalase or HRP was added to RoxA. Peroxidase at $1 \mu \mathrm{M}$ inhibited the cleavage reaction by $90 \%$ (catalase) or $65 \%$ (HRP). When hydrogen peroxide at a completely inhibitory concentration and catalase at a partially inhibitory concentration were added simultaneously, significant residual activities were determined that were of the same order as those in the presence of catalase alone. This result indicates that a peroxy compound could be an intermediate of the cleavage reaction. Other oxidizing compounds, such as potassium permanganate and potassium ferricyanide $(1 \mathrm{mM})$, partially inhibited RoxA by 70 and $80 \%$, respectively (Supplementary Table S2 and Table 2).

\section{Peroxidase activity of RoxA}

No significant peroxidase activity could be detected for purified RoxA in peroxidase assays using cytochrome $c$ or aromatic phenols such as pyrogallol, guaiacol and 4aminoantipyrene/2,4-dichlorophenol (Mason et al., 2001) as electron donors. All assays were negative in comparison 
with HRP, which served as positive control and which resulted in strong signals. A trace peroxidase activity was detected when $10^{3}$-fold or higher molar amounts of RoxA with respect to HRP were used. Assays of other enzymes containing metal ions, such as catalase and lipoxygenase, also resulted in minor activity at high enzyme concentrations that was even stronger than the one detected for RoxA. We conclude that RoxA has no significant peroxidase activity and that the trace activity can be attributed to a non-specific background that results simply from the presence of metal centres.

\section{EPR of RoxA in the presence of substrate and potential ligands}

The addition of imidazole to RoxA as isolated resulted in the disappearance of the high-spin signal at $g=6.1$ (Fig. 4a) and confirmed that imidazole is able to react with one haem centre. Incubation of RoxA with latex did not result in detectable qualitative changes of the EPR spectrum. In particular, the high-spin signal was still present regardless of whether high latex concentrations and/or long incubation times were applied (range of minutes to hours tested). However, the intensity of the haem signals decreased slightly in the presence of latex. This was more pronounced when dioxygen was removed and replaced by argon (Fig. $4 b)$. Interestingly, a weak signal at $g=2.16$ appeared in the absence of dioxygen after several hours of incubation and indicated the presence of an organic radical. When EPR measurements were performed in the presence of $\alpha$ tocopherol or $\beta$-carotene (instead of latex), the same signal at $g=2.16$ was detected after short incubation times (Fig. 4c). No combination of RoxA assay conditions was found (e.g. presence or absence of latex, dioxygen, dinitrogen or time of incubation) that resulted in a decrease of any of the high- or low-spin signals in EPR measurements by $50 \%$ or more. A complete disappearance of the haem signals was only observed after reduction with dithionite in the absence of dioxygen.

\section{DISCUSSION}

The recently discovered extracellular rubber-oxidizing enzyme RoxA of Xanthomonas sp. 35Y cleaves poly(cis1,4-isoprene) to give ODTD as the major degradation product by a yet unknown reaction mechanism. The amino acid sequence of RoxA ( $71.5 \mathrm{kDa}$ for the mature protein) harbours two motifs for covalently attached haems $(\mathrm{CXXCH})$ and has an additional approximately 20 amino acid-long sequence that is conserved in CCPs. This amino acid sequence includes a conserved histidine residue in the consensus sequence ' $\mathrm{P}^{* *} \mathrm{H}_{517} \mathrm{NGSVP}$ ', where an asterisk signifies an amino acid with a hydrophobic side chain (Jendrossek \& Reinhardt, 2003). His ${ }_{517}$ corresponds to His $_{261}, \mathrm{His}_{275}$ and $\mathrm{His}_{244}$ in P. aeruginosa, Paracoccus pantotrophus (previously Paracoccus denitrificans) and $N$. europaea CCPs, respectively (McGinnity et al., 1996; Fülöp et al., 1995; Ellfolk et al., 1983; Shimizu et al., 2001). These similarities suggest that RoxA is somehow related to bacterial CCPs and that $\mathrm{His}_{517}$ could have a role in electron transfer between the two centres. On the other hand, all attempts to demonstrate peroxidase activity of RoxA failed, despite the use of a set of different electron donors. Another difference from CCPs is the finding that RoxA is active only in the fully oxidized state (Table 1 ). Most CCPs must be converted to the mixed-valence state to become active (Echalier et al., 2006) or, as in the case of $N$. europaea CCP, are active in both the oxidized and the half-reduced form (Arciero \& Hooper, 1994). RoxA also differs from bacterial CCPs in the small difference in the redox potentials of the two haem centres (Table 1). While the high- and low-potential haem redox potentials of conventional bacterial CCPs differ by more than $0.6 \mathrm{~V}$ (Ellfolk et al., 1983; Arciero \& Hooper, 1994), a difference of less than $100 \mathrm{mV}$ was found for RoxA. The highpotential haem is His-Met-coordinated in bacterial CCPs (Shimizu et al., 2001). In RoxA, there is probably a bis-His coordination that causes a much more negative potential. This result resembles findings reported for the redox titration of the dihaem protein DHC2 from Geobacter sulfurreducens (Heitmann \& Einsle, 2005), which has two haem centres with axial bis-histidinyl coordination. The potential of the second haem was also not resolvable. The nona-haem cytochrome $c$ from Desulfovibrio desulfuricans (Fritz et al., 2001) contains nine haem groups with midpoint potentials of -100 to $-200 \mathrm{mV}$, whose single potentials are barely distinguishable. The small difference in midpoint potentials of the RoxA haem centres is apparently the reason why it was not possible to obtain the half-reduced state of RoxA in which one haem is completely reduced while the other haem is still oxidized. Similar results have been described for the $42 \mathrm{kDa}$ dihaem $c$-type protein MauG, which is required for the biosynthesis of tryptophan tryptophylquinone, the prosthetic group of methylamine dehydrogenase (MADH) ( $\mathrm{Li}$ et al., 2006). In comparison with RoxA, MauG has comparable amino acid similarities to CCPs and also has no peroxidase activity. The authors attribute the MauG midpoint potential values of -159 and $-244 \mathrm{mV}$ to a first and second one-electron reduction in an electron-connected system with two equivalent haems (Wang et al., 2003). However, unlike RoxA, MauG has only one $\alpha$-band signal at $550 \mathrm{~nm}$ in the fully reduced state instead of a split signal originating from two separate haems, as in RoxA. Therefore, and because of the preferential reduction of one haem (549 $\mathrm{nm} \alpha$-band) by dithionite or by NADH/ PMS (Fig. 1b, c), we conclude that the two haem centres of RoxA are not equivalent.

It should be emphasized that RoxA, unlike many bacterial peroxidases, is an extracellular enzyme that is secreted to the environment and is active without hydrogen peroxide or other cofactors (Table 1) (Braaz et al., 2004; Gilmour et al., 1994; Kobayashi et al., 1989; Pauleta et al., 2001; Thomas \& Stocker, 1999). Hydrogen peroxide even inhibits 

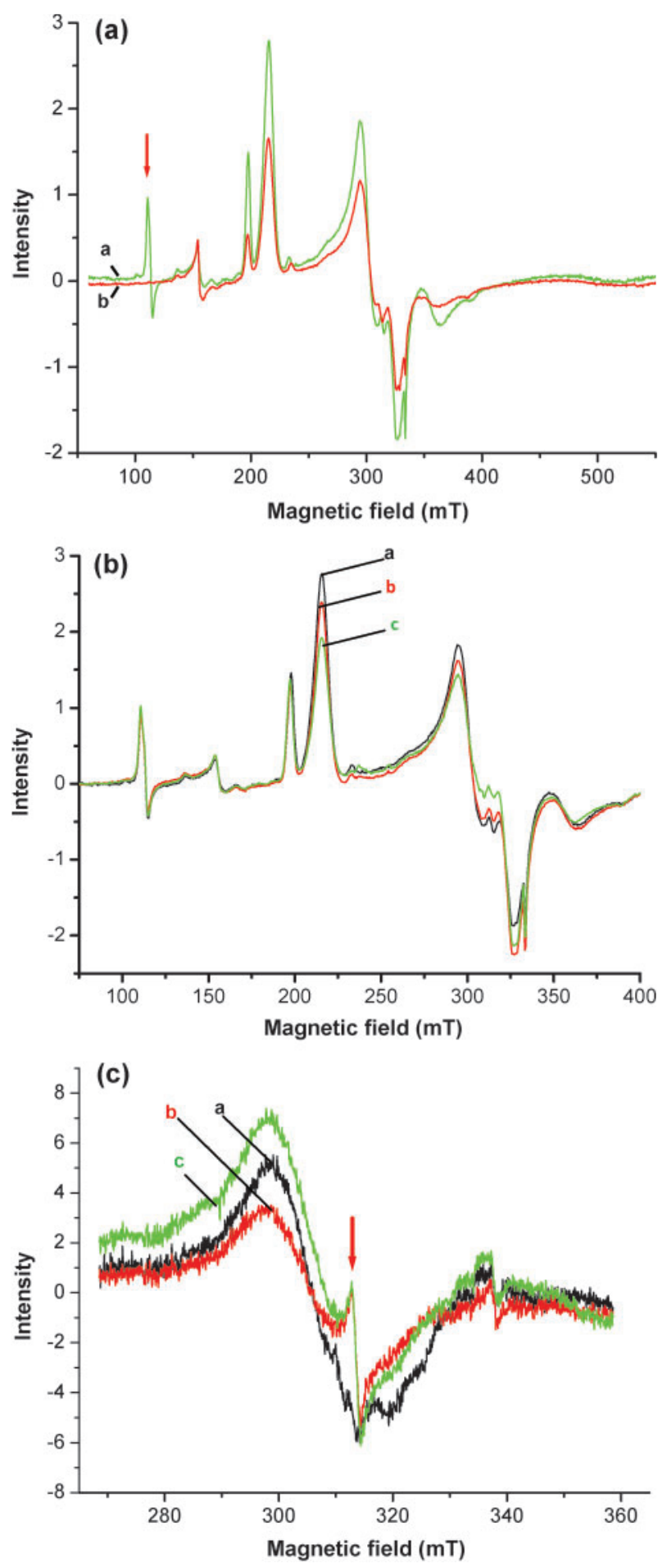

the reaction. RoxA does not need reductants for activity such as cytochrome $c$ in CCPs. Ions such as $\mathrm{Ca}^{2+}$ that are important for P. aeruginosa (Echalier et al., 2008) and Paracoccus pantotrophus CCPs (Pauleta et al., 2008) are not essential for RoxA and do not change the EPR signals, in contrast to peroxidases. RoxA is insensitive to high concentrations $(10 \mathrm{mM})$ of chelating agents such as EDTA (Braaz et al., 2004). All the data mentioned above
Fig. 4. (a) Overlay EPR spectra of RoxA as isolated $\left(\sim 5 \mathrm{mg} \mathrm{ml}^{-1}\right)$ and RoxA with imidazole. The high-spin signal at $g=6.1$ (arrow) disappeared completely. Line 'a' (green), RoxA as isolated; line 'b' (red), RoxA+imidazole $(10 \mathrm{mM})$ incubated for $1 \mathrm{~h}$ at room temperature under aerobic conditions. (b) Overlay EPR spectra of RoxA as isolated ( $\mathrm{a}$, black), RoxA with rubber latex incubated for $10 \mathrm{~min}$ (b, red) or for $90 \mathrm{~min}$ (c, green) under argon atmosphere. (c) Part of the EPR spectrum of RoxA as isolated ( $\mathrm{a}$, black), with $\beta$ carotene (b, red) and with $\alpha$-tocopherol (c, green) incubated for $10 \mathrm{~min}$ at room temperature. An organic radical signal appears in the spectrum of RoxA with substrate analogues (red arrow) at around $g=2.1$ that is barely present in the as-isolated spectrum. The spectrum of RoxA with ascorbate remained unchanged. Ascorbate is an antioxidant, similar to $\beta$-carotene and $\alpha$ tocopherol, but has no structural similarity to isoprene compounds.

clearly show that RoxA is not a peroxidase and that it apparently uses a different reaction mechanism for polyisoprene cleavage. This is reasonable, as the function of RoxA is the oxidative cleavage of a carbon-carbon double bond of polyisoprene and not the reduction of hydrogen peroxide or another compound.

Noteworthy results were obtained when low-molecularmass compounds such as imidazole, pyrazine and related compounds were tested for their effects on the UV/vis spectrum and activity of RoxA. Imidazole and related compounds strongly inhibited RoxA activity (Supplementary Tables S2 and S3) and led to rapid spectral changes. Interestingly, pyrrole, in contrast to the structurally related pyrazole, had no significant effect on RoxA. In pyrrole, the free electron pair of the nitrogen atom is part of the aromatic ring and cannot serve as an electron donor for the haem iron. In pyrazole, the second nitrogen atom has a free electron pair that can react with the haem. Compounds with large side groups such as methyl groups in the direct vicinity of the nitrogen atom possessing the free electron pair (e.g. 2-methylimidazole, Fig. 3a) did not inhibit or only poorly inhibited RoxA and had only a small effect on the UV/vis spectrum. Apparently, a voluminous side group in the direct vicinity of the atom providing the free electron pair prevents binding to haem due to steric hindrance. When the side group is further away from the nitrogen atom, as in 1methylimidazole, the compound again has a strong effect on activity and the UV/vis spectrum. The optical effects summarized in Supplementary Table S3 mimic a partial reduction of one haem and are probably a consequence of orbital overlapping. This interpretation is supported by the finding that imidazole and the related compounds listed in Supplementary Table S3 affected only one of the two $\alpha$ bands $(549 \mathrm{~nm})$ (Fig. 1b). In contrast, the addition of dithionite or NADH/PMS increased both $\alpha$-bands (549 and $553 \mathrm{~nm}$ ) and indicated a true reduction of the $549 \mathrm{~nm}$ haem and a subsequent intramolecular electron transport to the $553 \mathrm{~nm}$ haem (Fig. 1c). Since EPR analysis showed that one haem is (partially) present in the high-spin state, it is likely that imidazole and related compounds become 
bound to this high-spin haem. The disappearance of the high-spin signal at $g=6$ in the presence of imidazole is in agreement with this conclusion. However, we did not observe the formation of a new Fe(III) low-spin signal.

The presence of two ferric Fe(III) ions in RoxA contradicts previous assumptions that the polyisoprene cleavage reaction begins with binding of dioxygen to an $\mathrm{Fe}$ (II) ion. Some evidence for partial and reversible binding of dioxygen to one haem iron was obtained from the weak spectral changes at $549 \mathrm{~nm}$ after replacement of an oxic by an anoxic (dinitrogen) atmosphere or by removal of dioxygen (vacuum). We assume that the reaction is initiated by binding of the polymeric substrate to RoxA. The detection of a haem centre that was partially high spin, and the finding that polyisoprene cleavage cannot proceed if the sixth coordination site of this haem is occupied (e.g. by imidazole), suggest that the free coordination sphere is the location of the substrate cleavage reaction. Consequently, the polymeric substrate has to be placed in close proximity to the catalytic iron. This would require, however, either that the high-spin haem is located at the surface of the protein or that RoxA has a channel or cleft large enough to take up the polymeric substrate. This haem is accessible principally to small ligands (see above, Fig. 4a). The observation that RoxA activity in the presence of imidazole or related compounds was strongly decreased in a concentration-dependent manner, but was not completely inhibited even by high imidazole concentrations (10 mM, Supplementary Table S2), could be indicative of a competition between polyisoprene and/or dioxygen and the low-molecular-mass compounds for the substratebinding site. Alternatively, polyisoprene could be bound at the surface of RoxA at a so far unknown rubber-binding site. Polymer-specific substrate-binding sites are wellknown structures of other biopolymer-degrading enzymes, such as cellulases, chitinases, other glucohydrolases and polyhydroxyalkanoate depolymerases (Behrends et al., 1996; Gilkes et al., 1991; Hiraishi et al., 2010; RodriguezSanoja et al., 2005; Schrempf, 1999; Shinomiya et al., 1998). EPR data recorded for RoxA after aerobic incubation with latex did not lead to significant disappearance of the highspin signal, and accordingly a direct binding of latex to the high-spin haem is unlikely or could represent a short transient state that is difficult to observe experimentally. Experiments using reductants such as NADH/PMS or small compounds with free electron pairs showed that RoxA has an intrinsic capacity to abstract electrons from exogenous compounds. We do not know in which form these electrons are stored. One possibility is that the ferric iron is reduced to $\mathrm{Fe}(\mathrm{II})$; another is that an electron is stored by selected amino acids such as tyrosine and tryptophan. Reduction of ferric iron was clearly observed by reduction of RoxA with dithionite. In this case, both haems became diamagnetic and all the EPR signals disappeared.

When RoxA was incubated with latex in the absence of dioxygen, the EPR signals tentatively became less intense. This could indicate a reduction of $\mathrm{Fe}(\mathrm{III})$ to $\mathrm{Fe}(\mathrm{II})$ ions that give no EPR signals. However, quantification of EPR signals is problematic, as repeated recording of EPR data from the same RoxA preparation resulted in variable EPR signal intensities. Because of the low difference in midpoint potentials of the two haems $\left(\Delta E^{0 \prime} \sim 80 \mathrm{mV}\right)$ it is reasonable to suppose that a reduction at one haem would cause a subsequent reduction of the other haem instead of a preferred reduction of only one haem, which would explain why EPR signals became less intense. Data obtained from UV/vis spectroscopy during stepwise reduction were in agreement with this assumption (results not shown).

When EPR data were recorded with latex in the absence of dioxygen or with inhibiting substrate analogues such as $\beta$ carotene and $\alpha$-tocopherol, a minor signal at $g=2.16$ was detected (Fig. 4c). When the same experiment was performed with latex in the presence of air the signal indicative of an organic radical could barely be detected. These results indicate that RoxA is able to partially abstract an electron from a substrate and stabilize the resulting radical. The intermediate formation of organic radicals during catalysis is common for many oxygenases. The radical can be enzyme-bound or can be an enzyme (tyrosyl) radical (Ryle et al., 2003; Siegbahn \& Haeffner, 2004; Su et al., 1998). The remaining polyisoprene radical could combine with a dioxygen molecule and resume an electron, resulting in an intermediate peroxide that subsequently dissociates into the keto and aldehyde product ODTD. If we assume that the formation of the radical is a slow process relative to the reaction with dioxygen and to dissociation, the consequence is that no or only very little effect would be seen by EPR measurements in the presence of latex and that the signal indicative of the polyisoprene radical would be seen only in the absence of dioxygen. Note that the RoxA-catalysed cleavage of polyisoprene is a very slow process, with the specific activity of purified RoxA as low as $300 \mathrm{nmol} \mathrm{min}{ }^{-1} \mathrm{mg}^{-1}$ (Braaz et al., 2005). Accordingly, cultivation of Xanthomonas sp. on NR latex takes almost 2 weeks until a significant portion of the substrate has been consumed. We propose that a polyisoprenyl radical is formed in the rate-limiting step triggered by interaction of the substrate possibly with the high-spin haem centre or with an unknown part of RoxA followed by a reaction with dioxygen. The intermediate formation of a radical and of a peroxide is in agreement with the inhibition of the reaction by radical scavengers (ascorbate) and by peroxidases (catalase) (Table 2 and Supplementary Table S2). Future experiments should address the role of each of the haem centres and the importance of potentially electrontransferring amino acid residues such as $\mathrm{His}_{517}$.

\section{ACKNOWLEDGEMENTS}

This work was supported by a grant from the Deutsche Forschungsgemeinschaft to D.J. We thank J. Altenbuchner, University of Stuttgart, for providing p4782.1 and Marc Rudolf for support in some experiments. 


\section{REFERENCES}

Arciero, D. M. \& Hooper, A. B. (1994). A di-heme cytochrome $c$ peroxidase from Nitrosomonas europaea catalytically active in both the oxidized and half-reduced states. J Biol Chem 269, 11878-11886.

Arslan, E., Schulz, H., Zufferey, R., Kunzler, P. \& Thöny-Meyer, L. (1998). Overproduction of the Bradyrhizobium japonicum c-type cytochrome subunits of the $\mathrm{Cbb}_{3}$ oxidase in Escherichia coli. Biochem Biophys Res Commun 251, 744-747.

Behrends, A., Klingbeil, B. \& Jendrossek, D. (1996). Poly(3hydroxybutyrate) depolymerases bind to their substrate by a C-terminal located substrate binding site. FEMS Microbiol Lett 143, 191-194.

Bode, H. B., Zeeck, A., Plückhahn, K. \& Jendrossek, D. (2000). Physiological and chemical investigations into microbial degradation of synthetic poly(cis-1,4-isoprene). Appl Environ Microbiol 66, 36803685.

Bode, H. B., Kerkhoff, K. \& Jendrossek, D. (2001). Bacterial degradation of natural and synthetic rubber. Biomacromolecules 2 , 295-303.

Braaz, R., Fischer, P. \& Jendrossek, D. (2004). Novel type of hemedependent oxygenase catalyzes oxidative cleavage of rubber (poly-cis1,4-isoprene). Appl Environ Microbiol 70, 7388-7395.

Braaz, R., Armbruster, W. \& Jendrossek, D. (2005). Heme-dependent rubber oxygenase RoxA of Xanthomonas sp. cleaves the carbon backbone of poly(cis-1,4-isoprene) by a dioxygenase mechanism. Appl Environ Microbiol 71, 2473-2478.

Bradford, M. M. (1976). A rapid and sensitive method for the quantitation of microgram quantities of protein utilizing the principle of protein-dye binding. Anal Biochem 72, 248-254.

Echalier, A., Goodhew, C. F., Pettigrew, G. W. \& Fulop, V. (2006). Activation and catalysis of the di-heme cytochrome $c$ peroxidase from Paracoccus pantotrophus. Structure 14, 107-117.

Echalier, A., Brittain, T., Wright, J., Boycheva, S., Mortuza, G. B., Fulop, V. \& Watmough, N. J. (2008). Redox-linked structural changes associated with the formation of a catalytically competent form of the diheme cytochrome $c$ peroxidase from Pseudomonas aeruginosa. Biochemistry 47, 1947-1956.

Ellfolk, N., Ronnberg, M., Aasa, R., Andreasson, L. E. \& Vanngard, T. (1983). Properties and function of the two hemes in Pseudomonas cytochrome $c$ peroxidase. Biochim Biophys Acta 743, 23-30.

Fritz, G., Griesshaber, D., Seth, O. \& Kroneck, P. M. (2001). Nonaheme cytochrome $c$, a new physiological electron acceptor for [Ni,Fe] hydrogenase in the sulfate-reducing bacterium Desulfovibrio desulfuricans Essex: primary sequence, molecular parameters, and redox properties. Biochemistry 40, 1317-1324.

Fülöp, V., Ridout, C. J., Greenwood, C. \& Hajdu, J. (1995). Crystal structure of the di-haem cytochrome $c$ peroxidase from Pseudomonas aeruginosa. Structure 3, 1225-1233.

Gilkes, N. R., Henrissat, B., Kilburn, D. G., Miller, R. C., Jr \& Warren, R. A. (1991). Domains in microbial beta-1,4-glycanases: sequence conservation, function, and enzyme families. Microbiol Rev 55, 303 315.

Gilmour, R., Goodhew, C. F., Pettigrew, G. W., Prazeres, S., Moura, J. J. \& Moura, I. (1994). The kinetics of the oxidation of cytochrome $c$ by Paracoccus cytochrome $c$ peroxidase. Biochem J 300, 907-914.

Hambsch, N., Schmitt, G. \& Jendrossek, D. (2010). Development of a homologous expression system for rubber oxygenase RoxA from Xanthomonas sp. J Appl Microbiol, (in press)

Heitmann, D. \& Einsle, O. (2005). Structural and biochemical characterization of DHC2, a novel diheme cytochrome $c$ from Geobacter sulfurreducens. Biochemistry 44, 12411-12419.
Hiraishi, T., Komiya, N., Matsumoto, N., Abe, H., Fujita, M. \& Maeda, M. (2010). Degradation and adsorption characteristics of PHB depolymerase as revealed by kinetics of mutant enzymes with amino acid substitution in substrate-binding domain. Biomacromolecules 11, 113119.

Hopkins, N. \& Williams, C. H., Jr (1995). Lipoamide dehydrogenase from Escherichia coli lacking the redox active disulfide: C44S and C49S. Redox properties of the FAD and interactions with pyridine nucleotides. Biochemistry 34, 11766-11776.

Jendrossek, D. \& Reinhardt, S. (2003). Sequence analysis of a gene product synthesized by Xanthomonas sp. during growth on natural rubber latex. FEMS Microbiol Lett 224, 61-65.

Jendrossek, D., Tomasi, G. \& Kroppenstedt, R. M. (1997). Bacterial degradation of natural rubber: a privilege of actinomycetes? FEMS Microbiol Lett 150, 179-188.

Katz, I. \& Keeney, M. (1966). Quantitative micro determination and isolation of plasmalogen aldehydes as 2,4-dinitrophenylhydrazones. J Lipid Res 7, 170-174.

Kobayashi, K., Hayashi, K. \& Sono, M. (1989). Effects of tryptophan and $\mathrm{pH}$ on the kinetics of superoxide radical binding to indoleamine 2,3-dioxygenase studied by pulse radiolysis. J Biol Chem 264, 1528015283 .

Li, X., Feng, M., Wang, Y., Tachikawa, H. \& Davidson, V. L. (2006). Evidence for redox cooperativity between $c$-type hemes of MauG which is likely coupled to oxygen activation during tryptophan tryptophylquinone biosynthesis. Biochemistry 45, 821-828.

Linos, A., Steinbüchel, A., Sproer, C. \& Kroppenstedt, R. M. (1999). Gordonia polyisoprenivorans sp. nov., a rubber-degrading actinomycete isolated from an automobile tyre. Int J Syst Bacteriol 49, 17851791.

Linos, A., Berekaa, M. M., Steinbüchel, A., Kim, K. K., Sproer, C. \& Kroppenstedt, R. M. (2002). Gordonia westfalica sp. nov., a novel rubber-degrading actinomycete. Int J Syst Evol Microbiol 52, 11331139.

Mason, M. G., Ball, A. S., Reeder, B. J., Silkstone, G., Nicholls, P. \& Wilson, M. T. (2001). Extracellular heme peroxidases in actinomycetes: a case of mistaken identity. Appl Environ Microbiol 67, 45124519.

Massey, V. \& Hemmerich, P. (1978). Photoreduction of flavoproteins and other biological compounds catalyzed by deazaflavins. Biochemistry 17, 9-16.

McGinnity, D. F., Devreese, B., Prazeres, S., Van Beeumen, J., Moura, I., Moura, J. J. \& Pettigrew, G. W. (1996). A single histidine is required for activity of cytochrome $c$ peroxidase from Paracoccus denitrificans. J Biol Chem 271, 11126-11133.

Neese, F. (1995). The EPR program. Quantum Chemistry Program Exchange Bulletin 15, 5.

Palmer, G. (1983). Electron Paramagnetic Resonance of Hemoproteins. Reading, MA: Addison-Wesley.

Pauleta, S. R., Lu, Y., Goodhew, C. F., Moura, I., Pettigrew, G. W. \& Shelnutt, J. A. (2001). Calcium-dependent conformation of a heme and fingerprint peptide of the diheme cytochrome $c$ peroxidase from Paracoccus pantotrophus. Biochemistry 40, 6570-6579.

Pauleta, S. R., Lu, Y., Goodhew, C. F., Moura, I., Pettigrew, G. W. \& Shelnutt, J. A. (2008). Calcium-dependent heme structure in the reduced forms of the bacterial cytochrome $c$ peroxidase from Paracoccus pantotrophus. Biochemistry 47, 5841-5850.

Rodriguez-Sanoja, R., Oviedo, N. \& Sanchez, S. (2005). Microbial starch-binding domain. Curr Opin Microbiol 8, 260-267.

Rose, K. \& Steinbüchel, A. (2005). Biodegradation of natural rubber and related compounds: recent insights into a hardly understood 
catabolic capability of microorganisms. Appl Environ Microbiol 71, 2803-2812.

Rose, K., Tenberge, K. B. \& Steinbüchel, A. (2005). Identification and characterization of genes from Streptomyces sp. strain K30 responsible for clear zone formation on natural rubber latex and poly(cis-1,4isoprene) rubber degradation. Biomacromolecules 6, 180-188.

Ryle, M. J., Liu, A., Muthukumaran, R. B., Ho, R. Y., Koehntop, K. D., McCracken, J., Que, L., Jr \& Hausinger, R. P. (2003). $\mathrm{O}_{2^{-}}$and $\alpha$ ketoglutarate-dependent tyrosyl radical formation in TauD, an $\alpha$-keto acid-dependent non-heme iron dioxygenase. Biochemistry 42, 1854-1862.

Schrempf, H. (1999). Characteristics of chitin-binding proteins from streptomycetes. EXS 87, 99-108.

Shimizu, H., Schuller, D. J., Lanzilotta, W. N., Sundaramoorthy, M., Arciero, D. M., Hooper, A. B. \& Poulos, T. L. (2001). Crystal structure of Nitrosomonas europaea cytochrome $c$ peroxidase and the structural basis for ligand switching in bacterial di-heme peroxidases. Biochemistry 40, 13483-13490.

Shinomiya, M., Iwata, T. \& Doi, Y. (1998). The adsorption of substrate-binding domain of PHB depolymerases to the surface of poly(3-hydroxybutyric acid). Int J Biol Macromol 22, 129-135.

Siegbahn, P. E. \& Haeffner, F. (2004). Mechanism for catechol ringcleavage by non-heme iron extradiol dioxygenases. $\mathrm{J}$ Am Chem Soc 126, 8919-8932.

Su, C., Sahlin, M. \& Oliw, E. H. (1998). A protein radical and ferryl intermediates are generated by linoleate diol synthase, a ferric hemeprotein with dioxygenase and hydroperoxide isomerase activities. J Biol Chem 273, 20744-20751.

Tanaka, Y. \& Sakdapipanich, J. T. (2001). Chemical structure and occurrence of natural polyisoprenes. In Biopolymers, vol. 2
(Polyisoprenoids), pp. 1-25. Edited by A. Steinbüchel. Weinheim, Germany: Wiley-VCH.

Thomas, S. R. \& Stocker, R. (1999). Redox reactions related to indoleamine 2,3-dioxygenase and tryptophan metabolism along the kynurenine pathway. Redox Rep 4, 199-220.

Thöny-Meyer, L. (1997). Biogenesis of respiratory cytochromes in bacteria. Microbiol Mol Biol Rev 61, 337-376.

Tsuchii, A. \& Takeda, K. (1990). Rubber-degrading enzyme from bacterial culture. Appl Environ Microbiol 56, 269-274.

Tsuchii, A., Suzuki, T. \& Takeda, K. (1985). Microbial degradation of natural rubber vulcanisates. Appl Environ Microbiol 50, 965-970.

Walker, F. A. (1999). Magnetic spectroscopy (EPR, ESEEM, Mösbauer, MCD, and NMR) studies of low-spin ferriheme centers and their corresponding heme proteins. Coord Chem Rev 185-186, 471-534.

Wang, Y., Graichen, M. E., Liu, A., Pearson, A. R., Wilmot, C. M. \& Davidson, V. L. (2003). MauG, a novel diheme protein required for tryptophan tryptophylquinone biogenesis. Biochemistry 42, 73187325.

Wariishi, H., Nonaka, D., Johjima, T., Nakamura, N., Naruta, Y., Kubo, S. \& Fukuyama, K. (2000). Direct binding of hydroxylamine to the heme iron of Arthromyces ramosus peroxidase. Substrate analogue that inhibits compound I formation in a competitive manner. J Biol Chem 275, 32919-32924.

Zahn, J. A., Arciero, D. M., Hooper, A. B., Coats, J. R. \& DiSpirito, A. A. (1991). Cytochrome $c$ peroxidase from Methylococcus capsulatus Bath. Arch Microbiol 168, 362-372.

Edited by: M. Tien 